\title{
Parkes Weber syndrome associated with two somatic pathogenic variants in RASA1
}

\author{
Josue A. Flores Daboub, ${ }^{1}$ Johanes Fred Grimmer, ${ }^{2}$ Alice Frigerio, ${ }^{3}$ \\ Whitney Wooderchak-Donahue, ${ }^{4,5}$ Ryan Arnold, ${ }^{6}$ Jeff Szymanski, ${ }^{7}$ \\ Nicola Longo, ${ }^{1,4}$ and Pinar Bayrak-Toydemir ${ }^{4,5}$ \\ ${ }^{1}$ Division of Pediatric Genetics, University of Utah School of Medicine, Salt Lake City, Utah 84108, USA; \\ ${ }^{2}$ Division of Ear, Nose, and Throat, University of Utah, Salt Lake City, Utah 84108, USA; ${ }^{3}$ Division of \\ Dermatology, University of Utah School of Medicine, Salt Lake City, Utah 84108, USA; ${ }^{4}$ Department of \\ Pathology, ${ }^{5}$ ARUP Institute for Clinical and Experimental Pathology, University of Utah, Salt Lake City, \\ Utah 84108, USA; ${ }^{6}$ Primary Children's Hospital Interventional Radiology, Salt Lake City, Utah 84113, USA; \\ ${ }^{7}$ Department of Radiation Oncology, Washington University, St. Louis, Missouri 63130, USA
}

Corresponding author: Josue.flores@hsc.utah.edu

(C) 2020 Flores Daboub et al. This article is distributed under the terms of the Creative Commons Attribution-NonCommercial License, which permits reuse and redistribution, except for commercial purposes, provided that the original author and source are credited.

\section{Ontology terms:}

hemihypertrophy; lower limb asymmetry; overgrowth; prominent superficial veins

Published by Cold Spring Harbor Laboratory Press

doi:10.1101/mcs.a005256
Abstract Parkes Weber syndrome is associated with autosomal dominant inheritance, caused by germline heterozygous inactivating changes in the RASA1 gene, characterized by multiple micro arteriovenous fistulas and segmental overgrowth of soft tissue and skeletal components. The focal nature and variable expressivity associated with this disease has led to the hypothesis that somatic "second hit" inactivating changes in RASA1 are necessary for disease development. We report a 2-yr-old male with extensive capillary malformation and segmental overgrowth of his lower left extremity. Ultrasound showed subcutaneous phlebectasia draining the capillary malformation; magnetic resonance imaging showed overgrowth of the extremity with prominence of fatty tissues, fatty infiltration, and enlargement of all the major muscle groups. Germline RASA1 testing was normal. Later somatic testing from affected tissue showed two pathogenic variants in RASA1 consistent with the c.934_938del, p.(Glu312Argfs*14) and the c.2925del, p.(Asn976Metfs*20) with variant allele fractions of $3.6 \%$ and $4.2 \%$, respectively. The intrafamilial variability of Parkes Weber syndrome involving segmental overgrowth of soft tissue, endothelium, and bone is strongly suggestive of a somatic second-hit model. There are at least two reports of confirmed second somatic hits in RASA1. To our knowledge, this is the first report of an individual with two somatic pathogenic variants in the RASA1 gene in DNA from a vascular lesion.

\section{INTRODUCTION}

Parkes Weber syndrome (PKWS; MIM \# 608355) is associated with autosomal dominant inheritance, caused by germline heterozygous inactivating variants in the RASA1 gene (Eerola et al. 2003) (MIM \# 139150). Multiple micro arteriovenous fistulas (AVFs) and segmental overgrowth of soft tissue and skeletal components are characteristic of PKWS (Revencu et al. 2008). Clinically, the capillary stains associated with RASA1-related syndromes can be distinguished from regular capillary malformations (CMs) or port wine stains by a pale halo around the stain and because they increase in number with age (Revencu et al. 2013). The intrafamilial variability and the multifocal lesions in PKWS involving segmental overgrowth of soft tissue, endothelium, and bone are strongly suggestive of a somatic second-hit model (Lapinski 
et al. 2018). Here, we present an individual with PKWS in which RASA1 germline testing was negative. Subsequent molecular testing of CM tissue identified two somatic RASA1 pathogenic variants.

\section{RESULTS}

\section{Clinical Presentation and Family History}

The affected individual was a 2-yr-old Caucasian male with extensive CMs and segmental overgrowth affecting primarily the left leg. Pregnancy was uncomplicated, and he was appropriate for gestational age. He was initially evaluated by Dermatology for cutaneous CM consistent with two large macular vascular stains: one that extends into the genital area and onto the left buttock, and the other one on the left leg circumferentially extending to the top of the left foot (Fig. 1). Segmental overgrowth of his left leg was noticed at $\sim 6$ mo of age.

At 6 mo of age, genetic testing of peripheral blood DNA indicated normal results from chromosomal microarray analysis and germline RASA1 gene sequencing with deletion
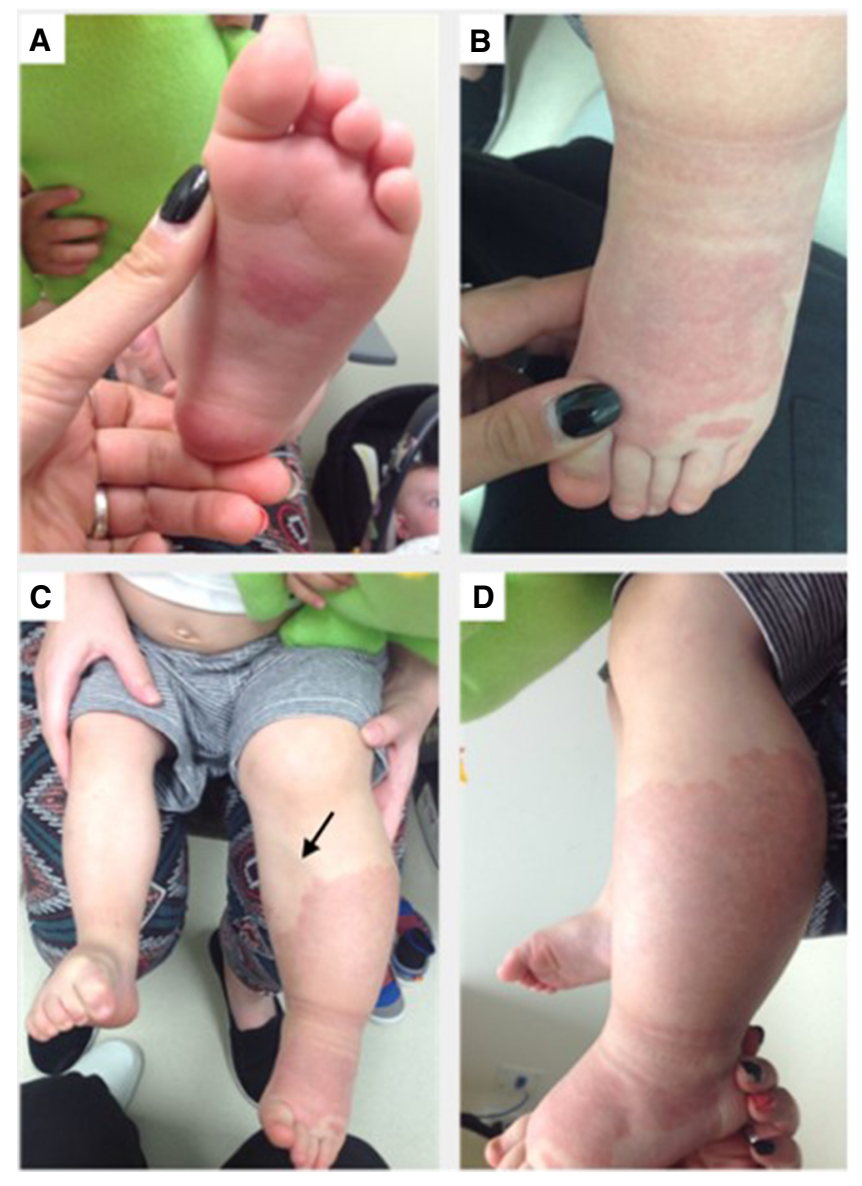

Figure 1. Capillary malformations on the left lower leg, associated with segmental overgrowth. (A) Sole of left foot showing a rounded capillary stain in the middle. (B) Dorsal aspect of left foot with a large capillary stain and a pale halo around its borders. (C) Prominent superficial vein of the left leg (arrow). (D) Left leg affected with a diffuse cutaneous capillary malformation and significant segmental overgrowth. 
COLD SPRING HARBOR Molecular Case Studies
Phenotypic heterogeneity of somatic RASA1 variants

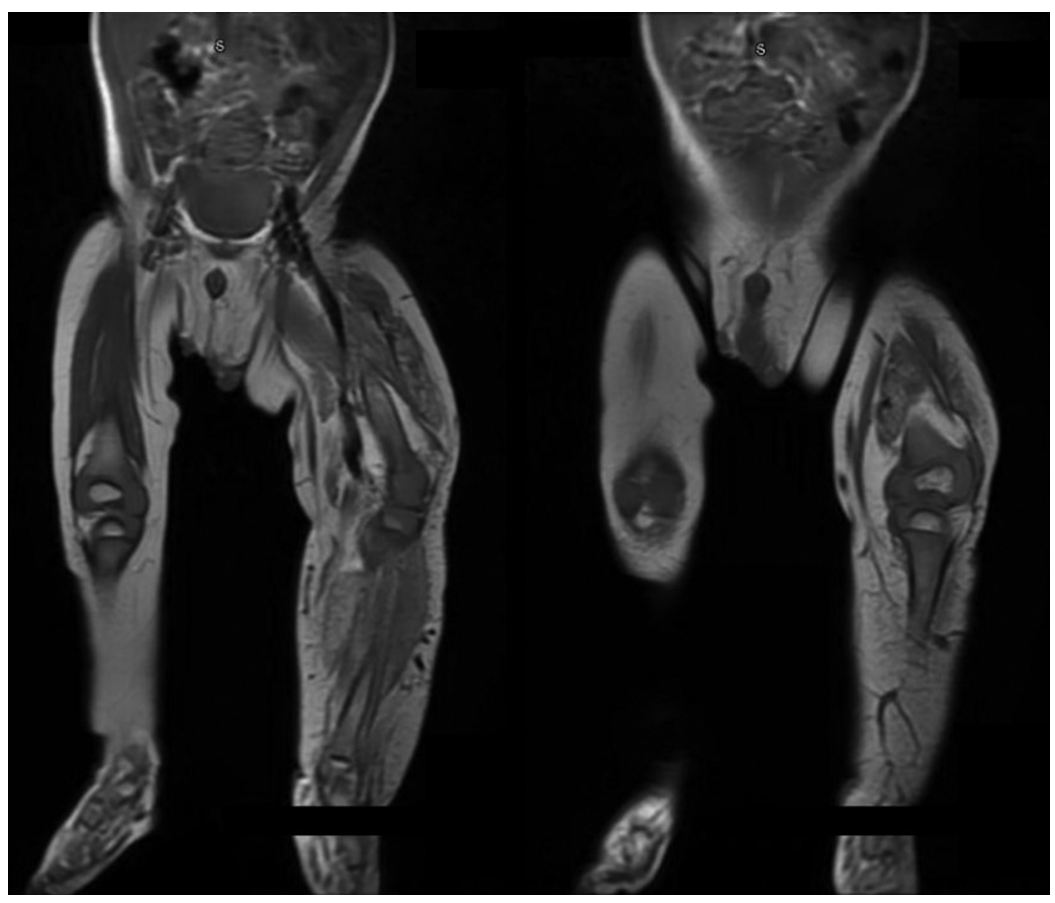

Figure 2. Magnetic resonance imaging of the lower legs showing overgrowth of soft tissue and diffuse enlargement of the vasculature on the left.

and duplication analysis. Complete abdominal ultrasound and brain MRI were normal. An ultrasound of the left leg showed subcutaneous phlebectasia draining the CMs, without a cystic component or spongiform venous malformation.

There were several prominent subcutaneous veins extending from the foot up to the anterior and medial aspect of the shin and thigh. A magnetic resonance imaging (MRI) of the left leg showed overgrowth of the extremity with prominence of fatty tissues, fatty infiltration, and enlargement of all of the major muscle groups. In addition, there was diffuse enlargement of the vasculature, compatible with increased flow through the cutaneous $\mathrm{CMs}$, and prominent subcutaneous varicose venous system draining in the greater saphenous distribution (Fig. 2).

\section{Genomic Analysis}

A skin biopsy at age $2 \mathrm{yr}$ from tissue affected with overgrowth and capillary malformation showed two somatic pathogenic variants in RASA1 c.934_938del p.(Glu312Argfs*14) and c.2925del p.(Asn976Metfs*20) with variant allele fractions of $3.6 \%$ and $4.2 \%$, respectively (Table 1; Fig. 3). Both variants were classified as pathogenic because they both cause the premature insertion of termination codons (PVS1), are not present in available databases (gnomAD, PM2), and are presumed de novo (PM6). Both the biological parents were examined and had no visible or reported capillary malformations or port wine stains. Parental samples were not available for RASA1 genetic testing.

\section{DISCUSSION}

RASA1 encodes for the RAS p21 protein activator 1, which is part of the RAS gene family involved in the control of cellular proliferation and differentiation. The RAS proteins cycle 


\begin{tabular}{|c|c|c|c|c|c|c|c|c|}
\hline Gene & $\begin{array}{l}\text { Chromosome } \\
\text { (GRCh37.p13) }\end{array}$ & $\begin{array}{l}\text { HGVS DNA } \\
\text { reference }\end{array}$ & $\begin{array}{l}\text { HGVS protein } \\
\text { reference }\end{array}$ & $\begin{array}{l}\text { Variant } \\
\text { type }\end{array}$ & $\begin{array}{c}\text { Predicted } \\
\text { effect } \\
\text { (substitution, } \\
\text { deletion, etc.) }\end{array}$ & $\begin{array}{l}\text { dbSNP/ } \\
\text { dbVar } \\
\text { ID }\end{array}$ & $\begin{array}{c}\text { Genotype } \\
\text { (heterozygous/ } \\
\text { homozygous) }\end{array}$ & Comments \\
\hline RASA1 & $\begin{array}{l}\text { Chr 5: } \\
\text { g.86682720_- } \\
\text { 86682720delG }\end{array}$ & c. 2925 delG & p.Asn976Metfs*20 & Pathogenic & $\begin{array}{l}\text { 1-bp deletion } \\
\text { causes a } \\
\text { protein } \\
\text { frameshift }\end{array}$ & Novel & Somatic (4.2\%) & $\begin{array}{l}\text { Likely de } \\
\text { novo }\end{array}$ \\
\hline RASA1 & $\begin{array}{l}\text { Chr 5: } \\
\qquad \begin{array}{l}\text { g.86633825_- } \\
\text { 86633829del5 }\end{array}\end{array}$ & c.934_938del5 & p.Glu312Argfs*14 & Pathogenic & $\begin{array}{l}\text { 5-bp deletion } \\
\text { causes a } \\
\text { protein } \\
\text { frameshift }\end{array}$ & Novel & Somatic (3.6\%) & $\begin{array}{l}\text { Likely de } \\
\text { novo }\end{array}$ \\
\hline
\end{tabular}

Note that the NM_002890.2 and NP_002881.1 reference sequences were used for annotation.

between an active guanosine-triphosphate (GTP) bound form and an inactive, guanosinediphosphate (GDP) bound form.

Abnormalities in the RASA1 gene have been implicated in Parkes Weber syndrome (MIM \# 608355), characterized by cutaneous capillary malformation associated with underlying multiple micro-AVFs and soft tissue and skeletal hyperplasia of the affected limb (Boyd et al. 1984). Germline-inactivating variants in the RASA1 gene are detected in 50\%-85\% of individuals affected with CM-arteriovenous malformation (AVM) or Parkes Weber syndromes (Eerola et al. 2003).

The intrafamilial variability and the multifocal lesions in PKWS involving segmental overgrowth of soft tissue, endothelium, and bone are strongly suggestive of a somatic second-hit model (Lapinski et al. 2018). To date, there are at least two case reports of confirmed second somatic hits in RASA1 (one germline and one somatic) (Revencu et al. 2013; Macmurdo et al. 2016; Gordo et al. 2019)—only one of them with proven somatic second hit in trans of the germline pathogenic change (Lapinski et al. 2018).

Given recent reports in the literature and collective clinical experience, there is increasing evidence to support that a substantial number of patients with segmental overgrowth syndromes (with or without vascular dysplasias) are caused by somatic pathogenic variants without necessarily having germline involvement (Gordo et al. 2018, 2019). A recent publication by Gordo et al. (2019) reported two unrelated occurrences of CM-AVM caused by constitutional RASA1 pathogenic mosaic variants detected in a blood sample and the affected tissue in one of the affected individuals. There was no evidence of a second hit identified in the affected tissue.

The presence of two different somatic variants in the affected tissue can be explained by different mechanisms. Affected cells within the tissue contain the two variants in trans, consistent with the assumed pathogenesis of PKWS. Alternatively, the two variants could be in cis. In this case, one of the two variants would become irrelevant as a result of nonsense-mediated RNA decay caused by the upstream variant. It is also possible that distinct affected cells within the tissue contain either c.934_938del or c.2925del, but not both, such that three distinct cell populations exist in the affected tissue. A likely possibility is that one of the two variants, either the c.934_938del or the c.2925del, occurred first with the second hit occurring in a subpopulation of cells that harbored the original variant, mimicking a precancerous state. Although not performed in this study, stranded RNA sequencing protocols in affected tissues should be able to distinguish whether the variants are in cis or trans and address some of the possible mechanisms described above. 


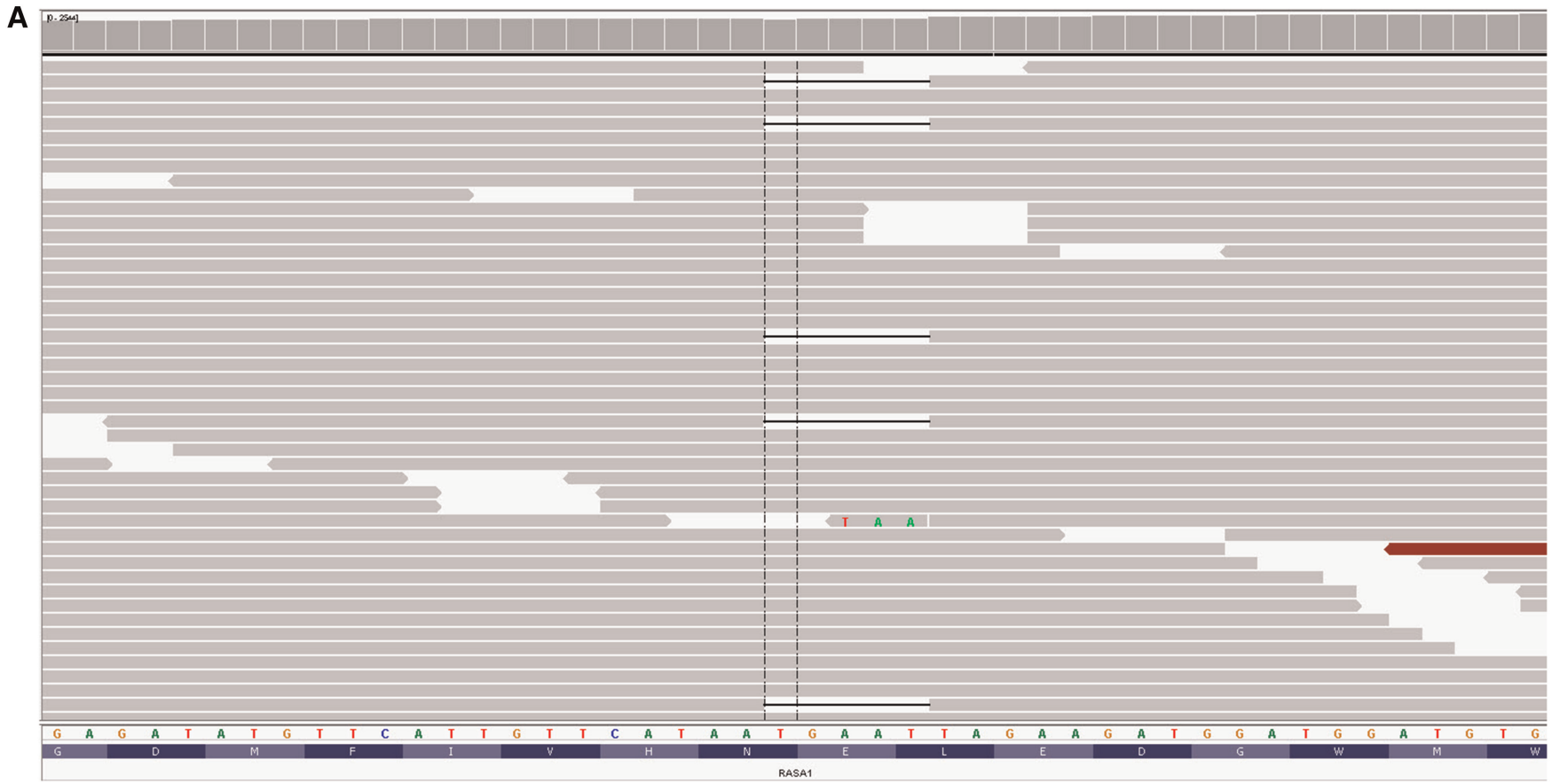

B

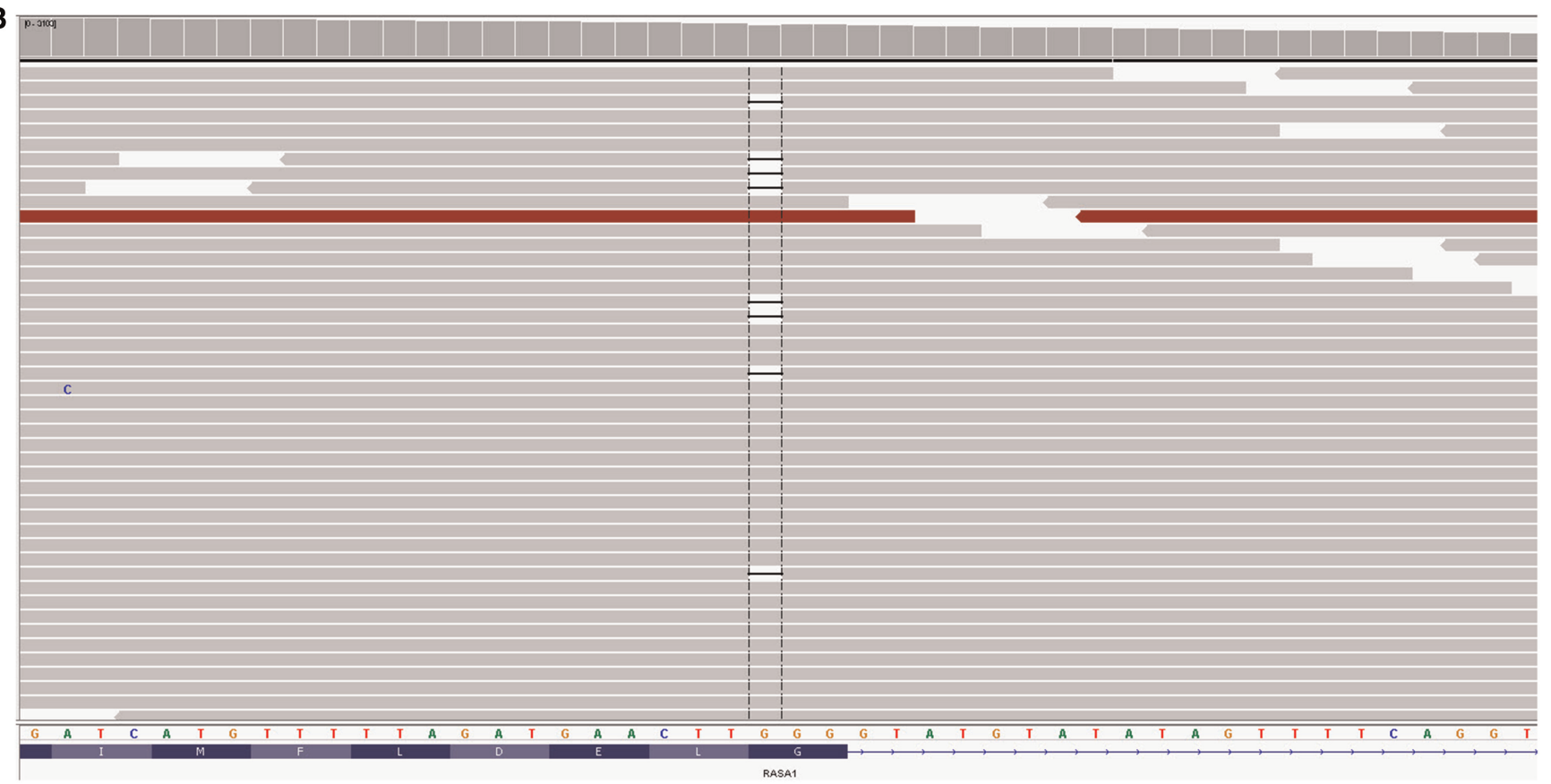

Figure 3. (A) Integrated Genomics Viewer (IGV) image of one somatic RASA1 c.934_938del, p. Glu312Argfs*14 variant detected at 3.6\% (73/2,038 reads) in the affected tissue. Chromosomal coordinates of the variant were as follows: Chr 5:86633825_86633829del5. (B) IGV image of a second RASA1 c.2925del, p.Asn976Metfs*20 variant detected at $4.2 \%(104 / 2,473$ reads) in the affected tissue. Chromosomal coordinates of the variant were as follows: Chr 5:86682720_86682720delG. 
COLD SPRING HARBOR Molecular Case Studies
Phenotypic heterogeneity of somatic RASA1 variants
Finally, the patient could have had one or both tissue-identified RASA1-inactivating variants in his germline detected via blood next-generation sequencing (NGS) DNA analysis, which was not obtained, or a different variant not detected by current NGS DNA analysis (e.g., a deep intronic variant, exon-level inversion not flagged by mismapping of the breakpoints). Under this scenario, the c.934_938del and the c.2925del variants could have been present in a subset of cells or have occurred independently on a background of sensitized tissue rather than on a background of normal (wild-type) tissue. Although possible, this is unlikely given that the same type of sequencing identified variants in the tissue, but not in blood. However, one of the caveats is that NGS was never performed in blood to completely rule out low-level mosaicism. Otherwise, the possibility of germline pathogenic variants in RASA1 noncoding regions is low.

\section{Conclusions}

In patients with clinical phenotypes consistent with RASA1 spectrum disorder (including CMAVM and PKWS), it is important to consider somatic genetic testing, particularly when the presentation is only localized to a specific segment of the body. Several independent studies have identified second-hit somatic variants in individuals affected with RASA1 germline pathogenic variants (Revencu et al. 2013; Macmurdo et al. 2016; Lapinski et al. 2018), including those with CM-AVM or PKWS. To our knowledge, this is the first report of a patient with two pathogenic somatic changes in the RASA1 gene without germline involvement. Nevertheless, stranded RNA sequencing protocols in affected tissues were not performed to distinguish whether the variants are in cis or trans.

\section{METHODS}

\section{Clinical Germline Sanger Sequencing Analysis (Blood)}

DNA was extracted from $1 \mathrm{~mL}$ of blood by MagnaPure Compact (Roche) extraction following manufacturer's instructions. RASA1 coding regions and exon-intron boundaries were PCR-amplified. Primer sequences are available upon request. Amplicon fragments were bidirectionally sequenced using universal M13 primers, the Big Dye Terminator v3.1 cycle sequencing kit, and an ABI 3730 DNA Analyzer (Life Technologies). Sequences were compared to the RASA1 reference sequence (NM_002890.2; NG_011650.1) using Mutation Surveyor (SoftGenetics).

\section{Clinical Germline Structural Variation Analysis (Blood)}

Large exonic deletions and duplications of RASA1 were interrogated for using the P409 RASA1 Multiplex Ligation-dependent Probe Amplification (MLPA) kit (MRC-Holland).

\section{Next-Generation Sequencing (Tissue)}

Targeted enrichment was performed using IDT xGen Lockdown probes (IDT Technologies) and the NimbleGen SeqCap EZ hybridization kit (Roche). Capture panel consisted of all coding regions with up to 10-bp flanking as well as selected introns for AKT1, AKT2, AKT3, FGFR1, GNA11, GNAQ, IDH1, IDH2, MAP2K1, MAP3K3, MTOR, PIK3CA, PIK3R1, PIK3R2, PTEN, RASA1, SMO, TEK, TSC1, and TSC2.

Libraries were constructed with KAPA HyperPrep Kit and KAPA Library Amplification Kit (Roche), and sequencing was performed on the HiSeq 2500 platform (Illumina) generating paired-end 101-bp reads. Reads were aligned against hg19 with NovoAlign v3.02. Variants were called with VarScan 2 v.2.3.6, Pindel v0.2.4d, BreakDancerMax v.1.1, and ClusterFast v.1.0. 
Competing Interest Statement The authors have declared no competing interest.

Received February 7, 2020; accepted in revised form July 8,2020
Unless known to be clinically relevant, variants with $>1 \%$ minor allele frequency (MAF) in dbSNP or gnomAD were classified as polymorphisms. Variants were reviewed in COSMIC v.80 and ClinVar, and pathogenicity was assessed by a board-certified molecular pathologist.

\section{Clinical Data}

This is a review of the medical records of a reported case. Medical evaluations were performed by a medical geneticist, pediatric dermatologist, and interventional radiologist. This report was approved by the Institutional Review Board at the University of Utah and written consent was obtained from the proband's family.

\section{ADDITIONAL INFORMATION}

\section{Data Deposition and Access}

The RASA1 variants were submitted to ClinVar (https://www.ncbi.nlm.nih.gov/clinvar/) and the ClinVar accession number for c.2925del is SCV001424307 and for c.934_938del is SCV001424308. In addition, the variants were added to the ARUP Laboratories Mutation database (https://arup.utah.edu/database/RASA1/RASA1_display.php).

\section{Ethics Statement}

Written consent was obtained under the Clinical Genetics Research Program: Phenotyping core IRB.

\section{AUTHOR CONTRIBUTIONS}

J.A.F.D. is the corresponding first author of this manuscript. N.L., P.B.-T., and W.W.-D. are the primary mentors on this publication. J.S. collaborated, providing information about the methods used for tissue analysis in the clinical laboratory at Washington University. J.F.G., A.F., and R.A. are part of our Vascular Anomalies Clinic and participated directly in this patient's evaluation, diagnosis, treatment, and management.

\section{REFERENCES}

Boyd BJ, Mulliken JB, Kaban LB, Upton JE III, Murray JE. 1984. Skeletal changes associated with vascular malformations. Plast Reconstr Surg 74: 789-795. doi:10.1097/00006534-198412000-00010

Eerola I, Boon LM, Mulliken JB, Burrows PE, Dompmartin A, Watanabe S, Vanwijck R, Vikkula M. 2003. Capillary malformation-arteriovenous malformation, a new clinical and genetic disorder caused by RASA1 mutations. Am J Hum Genet 73: 1240-1249. doi:10.1086/379793

Gordo G, Tenorio J, Arias P, Santos-Simarro F, García-Miñaur S, Moreno JC, Nevado J, Vallespin E, RodriguezLaguna L, Lapunzina P, et al. 2018. mTOR mutations in Smith-Kingsmore syndrome: four additional patients and a review. Clin Genet 93: 762-775. doi:10.1111/cge.13135

Gordo G, Rodriguez-Laguna L, Agra N, Mendez P, Feito M, Lapunzina P, Lopez-Gutierrez JC, Martinez-Glez V, et al. 2019. Constitutional mosaicism in RASA1-related capillary malformation-arteriovenous malformation Clin Genet 95: 516-519. doi:10.1111/cge.13499

Lapinski P, Doosti A, Salato V, North P, Burrows P, King P. 2018. Somatic second hit mutation of RASA1 in vascular endothelial cells in capillary malformation-arteriovenous malformation. Eur J Med Genet 61: 11-16. doi:10.1016/j.ejmg.2017.10.004

Macmurdo CF, Wooderchack-Donahue WL, Bayrak-Toydemir P, Le J, Wallenstein MB, Milla C, Teng JMC, Bernstein JA, Stevenson DA. 2016. RASA1 somatic mutation and variable expressivity in capillary malformation/arteriovenous malformation (CM/AVM) syndrome. Am J Med Genet 170: 1450-1454. doi:10.1002/ ajmg.a.37613 
Revencu N, Boon LM, Mulliken JB, Enjolras O, Cordisco MR, Burrows PE, Clapuyt P, Hammer F, Dubois J, Vikkula M, et al. 2008. Parkes Weber syndrome, vein of Galen aneurysmal malformation, and other fastflow vascular anomalies are caused by RASA1 mutations. Hum Mutat 29: 959-965. doi:10.1002/humu 20746

Revencu N, Boon LM, Mendola A, Cordisco MR, Dubois J, Clapuyt P, Hammer F, Amor DJ, Irvine AD, Vikkula $\mathrm{M}$, et al. 2013. RASA 1 mutations and associated phenotypes in 68 families with capillary malformationarteriovenous malformation. Hum Mutat 34: 1632-1641. doi:10.1002/humu.22431 


\section{COLD SPRING HARBOR Molecular Case Studies}

\section{Parkes Weber syndrome associated with two somatic pathogenic variants in RASA1}

Josue A. Flores Daboub, Johanes Fred Grimmer, Alice Frigerio, et al.

Cold Spring Harb Mol Case Stud 2020, 6: a005256

Access the most recent version at doi: $10.1101 /$ mcs.a005256

$\begin{array}{cl}\text { License } & \begin{array}{l}\text { This article is distributed under the terms of the Creative Commons } \\ \text { Attribution-NonCommercial License, which permits reuse and redistribution, except } \\ \text { for commercial purposes, provided that the original author and source are credited. }\end{array} \\ \text { Email Alerting } & \begin{array}{l}\text { Receive free email alerts when new articles cite this article - sign up in the box at the } \\ \text { Service right corner of the article or click here. }\end{array}\end{array}$

